\title{
Diálogos Interculturais entre Conhecimentos Tradicionais e Conhecimentos Científicos em uma Comunidade Geraizeira: um Olhar Freiriano na Licenciatura em Educação do Campo
}

Intercultural Dialogue between Traditional and Scientific Knowledge in a Geraizeira Community: a Freirean Approach to Teacher Training in Rural Education

\author{
(1]) Danilo Seithi Kato, ${ }^{(1)}$ Daniela Corsino Sandron, Marilisa Bialvo Hoffmann
}

Palavras-chave Resumo $\mathrm{O}$ presente estudo tem como objetivo analisar as Diálogos potencialidades de diálogos interculturais focados no ensino de Interculturais; Paulo Freire; Educação do

Campo;

Formação de

Professores de Ciências; Conhecimentos

Ecológicos

Tradicionais. ciências, a partir de um olhar freiriano ao percurso formativo e vivências de uma aluna do curso de Licenciatura em Educação do Campo da Universidade Federal do Triângulo Mineiro (Lecampo/ UFTM), pertencente a uma comunidade tradicional Geraizeira. Para tanto, foi realizada uma imersão etnográfica escolar na comunidade geraizeira de Pindaíba, em Rio Pardo de Minas-MG, com a finalidade de conhecer e experienciar sua realidade e modo de vida. A partir disso, emergiram três categorias de análise que desvelam a importância do genuíno diálogo entre culturas, no sentido proposto por Freire, quando pensamos a formação de professores e professoras de Ciências em contextos de Educação do Campo. Como resultados encontrados percebemos que a vivência e compartilhamento de conhecimentos tradicionais em uma comunidade é uma dinâmica muito presente entre os moradores e são compartilhados de geração para geração, como presenciado no cultivo de café sombreado. Por fim, concluímos que o reconhecimento em que a valorização se manifesta pela experiência entre espaços e tempos permite a construção de pontes entre os conhecimentos tradicionais em diálogo com os conhecimentos científicos construídos na escola/universidade e maximizados pela dinâmica da Pedagogia da Alternância.

Submetido em 05 de maio de 2021 Aceito para publicação em 31 de agosto de 2021 Publicado em 19 de setembro de 2021 
Keywords Abstract This study aims to analyze the potential of intercultural Intercultural exchanges on science teaching, using a Freirian perspective at the

Dialogues; formative path and experiences of an undergraduate student of a

Paulo Freire; teacher training course in rural Education at the Federal University Rural Education; of Triângulo Mineiro (Lecampo/UFTM), Brazil, belonging to a Science Teacher traditional Geraizeira community. For that matter, an ethnographic Training; immersion was carried out in the Geraizeira community of Pindaiba, Traditional in Rio Pardo de Minas-MG, in order to get to know and experience Ecological their reality and way of life. From this, three categories of analysis Knowledge. emerged that reveal the importance of genuine dialogue between cultures, in the sense proposed by Freire, when we think about the formation of science teachers in Rural Education. The results showed that living and sharing traditional knowledge in the community is a common practice among residents, which is shared from generation to generation. This was the case of shade-grown coffee. Lastly, we conclude that recognizing the value of experience throughout space and time allows the construction of communication between traditional and scientific knowledge, which starts at school and can be fully grasped with the dynamics of the Pedagogy of Alternation.

\section{Introdução}

O presente estudo aborda, a partir de um olhar freiriano, as potencialidades dos diálogos interculturais entre conhecimentos tradicionais e conhecimentos científicos, ocorridos a partir de uma pesquisa de cunho etnográfico realizada em uma comunidade tradicional Geraizeira ${ }^{1}$. Trata-se de um recorte de uma pesquisa de mestrado em Educação e traz elementos da perspectiva educacional de Paulo Freire, que nos auxiliam a pensar o papel da formação de professores e professoras de ciências nas Licenciaturas em Educação do Campo, como política pública que vislumbre a atuação da Universidade nas comunidades como ato dialógico. Neste sentido, que promova, portanto, situações gnosiológicas próprias da Educação libertadora tendo como horizonte a reforma agrária popular que opõe os sentidos das palavras extensão e comunicação (Freire, 2010, p. 07).

A implantação das Licenciaturas em Educação do Campo com formação por área de conhecimento nas Ciências da Natureza, ocorreu em um contexto de expansão do Ensino Superior que se deu com vigor na primeira década dos anos dois mil. Nesta ocasião, por conta do fomento à pesquisa, à formação de mestres e doutores, à abertura e interiorização de novas universidades e cursos, das políticas de ações afirmativas e, em

1 Os geraizeiros foram reconhecidos pelo governo federal somente em fevereiro de 2007, a partir do Decreto No 6.040, que instituiu a Política Nacional de Desenvolvimento Sustentável dos Povos e Comunidades Tradicionais. Em 2018, os geraizeiros receberam "Certidão de Autodefinição" pela Comissão Estadual para o Desenvolvimento Sustentável de Povos e Comunidades Tradicionais de Minas Gerais (CEPCT-MG). 
especial, de políticas públicas que ampararam todos estes processos, os povos do campo, das águas e das florestas finalmente conquistaram uma oportunidade real e objetiva de acesso ao Ensino Superior Público e gratuito. A partir do Programa Nacional de Educação do Campo (Pronacampo), 42 novos cursos de Licenciatura em Educação do Campo (LEDOC) foram inaugurados nas Universidades públicas brasileiras, através do Subprograma intitulado Programa de Apoio às Licenciaturas em Educação do Campo (Molina, 2015).

Neste sentido, compreendemos que a pesquisa da área de Educação em Ciências, em articulação com as pesquisas em Educação do Campo, tem problematizado a complexidade dos processos envolvidos na formação de professores e professoras de ciências no contexto das LEDOC. Andrade et al. (2019), ao analisarem onze edições do Encontro Nacional de Pesquisa em Educação em Ciências (ENPEC), destacam o quanto a pesquisa da área foi sendo retroalimentada com questões relacionadas às demandas dos povos do campo, na medida em que as políticas públicas para formação de professores e professoras foram sendo fomentadas com editais, tais como o Programa de Apoio às Licenciaturas em Educação do Campo (Procampo), vinculado à extinta Secretaria de Educação Continuada, Alfabetização, Diversidade e Inclusão (Secadi), do Ministério da Educação. Os mesmos autores enfatizam que o número de trabalhos relacionados à Educação do Campo e Ensino de Ciências praticamente dobrou numericamente nas últimas edições dos ENPEC, coincidindo exatamente com os 10 anos de implementação das Licenciaturas em Educação do Campo nas instituições de ensino superior brasileiras.

Tendo este contexto em vista, Brick et al. (2014) enfatizam a fecundidade da perspectiva freiriana de educação no enfrentamento dos desafios objetivos das LEDOC. De acordo com os autores, tanto pela aproximação dela com os princípios da Educação do Campo quanto pela potencialidade de articulação entre essa caminhada sóciohistórica, pensar esta formação nas LEDOC a partir de Paulo Freire "significa engajar-se com as realidades locais e suas transformações, reconhecendo os sujeitos do campo e a nós mesmos, como criadores e recriadores de conhecimento e da própria história" (Brick et al., 2014, p. 43). Desta maneira, pensar uma formação de professores e professoras de ciências, sensíveis à diversidade biocultural dos sujeitos que constituem a Educação do Campo, representa, ao mesmo tempo, uma demanda por uma educação intercultural.

Neste sentido, ao tratar-se da realidade objetiva das LEDOC, Melzer et al. (2021) apontam que é preciso a superação de um ensino de ciências pretensamente neutro, parcial e asséptico, para que este dê espaço às diversidades socioculturais locais que são muitas vezes invisibilizadas pela monocultura de valores, reflexo de um processo de homogeneização cultural, que põe em risco a própria sobrevivência da nossa e de diversas outras espécies de seres vivos. Os mesmos autores apontam que:

A Educação do Campo demanda um ensino de ciência da natureza engajado com as lutas sociais contra a ordem vigente, principalmente as que dão origem para a própria Educação do Campo. Não significa, com isso, apenas um ensino de ciências engajado com a transformação macrossocial, mas, também, engajado 
com as transformações macrossociais e locais, com a ruptura dos silenciamentos das diversas formas de agir num mundo igualmente diverso. $\mathrm{O}$ silenciamento das culturas e dos saberes é assim o silenciamento da diversidade natural que as produz dialeticamente, em nome de uma monocultura de saberes alienados da própria riqueza natural-cultural que o campo produz (Melzer et al., 2021, p. 189).

Especificamente, no presente artigo, trazemos o contexto formativo da Licenciatura em Educação do Campo da Universidade Federal do Triângulo Mineiro (Lecampo/UFTM), que tem como foco proporcionar educação em nível superior às populações rurais e do campo. É um curso relativamente novo no âmbito da UFTM e, atende principalmente, sujeitos da região chamada de Triângulo Mineiro, Noroeste e Norte do Estado de Minas Gerais e região nordeste do interior do Estado de São Paulo.

O curso segue uma estrutura de Pedagogia de Alternância, organizando-se didático-metodologicamente em duas temporalidades: o Tempo-Escola (presencial intensivo, em geral nos meses de janeiro e de julho) e o Tempo-Comunidade (alunos desenvolvem atividades em comunidades rurais, particularmente de sua origem e com acompanhamento dos professores e professoras da UFTM). Uma das comunidades do campo em que o curso atua é a dos Geraizeiros que, segundo Nogueira (2009), consiste na denominação dada aos camponeses da porção de Cerrado no Norte de Minas Gerais (os "Gerais") - paisagem que teve grande parte de sua extensão convertida em maciços de eucalipto, a partir da década de 1970. Segundo Pereira et al. (2020):

Os Geraizeiros reconhecem os Gerais como um patrimônio histórico e cultural, pois nessas terras viveram e vivem pessoas com um vasto conhecimento tradicional sobre o convívio com a biodiversidade e alternativas para convivência com a seca. As riquezas biológicas presentes no cerrado são de suma importância para a manutenção social desses povos e também da natureza em si, pois esse bioma é o segundo maior na América do Sul. As populações que vivem nesse bioma têm uma vida ecologicamente adaptada, e por conta disso os Geraizeiros foram reconhecidos como povos tradicionais do cerrado (Pereira et al., 2020, p. $54)$.

Dessa maneira, objetivamos analisar as potencialidades de diálogos interculturais focados no ensino de ciências, a partir de um olhar freiriano ao percurso formativo e vivências (na universidade e na comunidade) de uma aluna do curso de Licenciatura em Educação do Campo da Universidade Federal do Triângulo Mineiro (Lecampo/UFTM), pertencente a uma comunidade tradicional Geraizeira. Os diálogos interculturais, neste trabalho, podem ser entendidos em uma perspectiva de diálogo entre culturas, os quais representam diferentes olhares e interpretações sobre o mundo vivencial, fato que, frente a diferenças culturais, se mostram na diversidade da organização de trabalho, da economia, da relação com o ambiente, do pertencimento ao território, da religiosidade, da organização política, das relações humanas e de conhecimentos. 
Tais diálogos, devem ser interpretados para além do significado da ideia de conversa mediada por fala, mas podem ser percebidos em ações de aproximação de diferentes culturas, em formas não isoladas de interpretar o mundo (social, cultural e acadêmico). Para Freire (2015), o diálogo, enquanto ato comunicativo, não existe se alienamos a ignorância ao outro, isto é, se vemos a ignorância sempre no outro e nunca em nós mesmos. Do mesmo modo, o diálogo, no sentido freiriano, ocorre mediatizado pelo mundo, "não se esgotando na relação eu-tu" (Freire, 2003, p. 78).

Assim, o presente estudo investiga as possibilidades de aproximações entre o contexto de vida, o "estar sendo" da participante da pesquisa e conhecimentos científicos escolarizados próprios da educação em ciências. Essa aproximação se deu pela análise do contexto de vida da participante durante o Tempo Comunidade a partir de uma entrevista, bem como, análise do processo de produção do Trabalho de Conclusão de Curso (TCC) da mesma, que versou sobre a produção de cafés sombreados em sua comunidade e os diálogos interculturais com os conhecimentos das ciências da natureza.

O esforço em pensar diálogos interculturais se faz presente frente à intenção de não reproduzir o equívoco gnosiológico do modelo de extensão normalmente visto nas universidades. Um modelo pautado na "assistência técnica" que estende o conhecimento do contexto universitário para o campo, o que configura uma invasão cultural e uma ação antidialógica, que nada contribui para processos educativos "com" os sujeitos das comunidades, se configurando como uma educação "para" os sujeitos do campo (Freire 2010, p. 9).

A escolha em trabalhar com uma aluna do curso de Licenciatura em Educação do Campo é motivada pelos objetivos, especificidades e vivências que este curso proporciona aos seus estudantes. Destaca-se ainda, que esta escolha se deve ao fato da temática do TCC desenvolvido pela participante propiciar reflexões e discussões entre Conhecimentos Ecológicos Tradicionais (CET), representados pela prática dos cafés tradicionais e os Conhecimentos Científicos Ecológicos (CCE), derivados de conhecimentos da área das Ciências da Natureza. Acrescenta-se, o fato da participante ser moradora - Geraizeira - de uma comunidade tradicional.

A questão de pesquisa do presente estudo é enunciada da seguinte forma: que diálogos interculturais podem ser percebidos e/ou caracterizados na relação entre conhecimentos tradicionais e científicos inseridos no processo de construção de um TCC que tem como foco a produção de cafés especiais por parte de uma comunidade Geraizeira?

O objetivo principal do estudo foi, portanto, analisar as potencialidades de diálogos interculturais focados no ensino de ciências, a partir de um olhar freiriano ao percurso formativo e vivências (na universidade e na comunidade) de uma aluna do curso de Licenciatura em Educação do Campo da UFTM. 


\section{Educação intercultural na formação de professores de ciências do Campo: situação gnosiológica e pontes entre Conhecimentos Ecológicos Tradicionais e Conhecimentos Científicos Ecológicos}

Para situar a temática que se apresenta, realizamos um levantamento acerca das produções disponibilizadas em duas bases de dados: na Biblioteca Digital Brasileira de Teses e Dissertações (BDTD) e no Catálogo de teses da CAPES (T\&D), entre os anos de 2008-2018 período em que a referida dissertação foi desenvolvida. Através da busca pelo descritor "Educação Intercultural", encontramos na BDTD um total de 116 trabalhos. Com este mesmo descritor, no Catálogo T\&D CAPES, encontramos 241 trabalhos. Seguindo a mesma sistemática de busca, usando o descritor "Diálogos interculturais", a BDTD retornou a pesquisa com 27 trabalhos; já o catálogo T\&D CAPES, resultou o total de 111 trabalhos. Ao buscar pelo descritor "Educação Intercultural" AND "Ensino de Ciências" foram encontrados 4 trabalhos na BDTD e 2 trabalhos no catálogo T\&D CAPES. Refinando as buscas de modo a focalizar nosso olhar no tema de nossa pesquisa, centramos em trabalhos que trouxessem algumas temáticas correlacionadas, como: formação de professores, interculturalidade, educação do campo, ensino de ciências, em um contexto de "Diálogos Interculturais" e "Educação Intercultural".

Procedendo desta forma, após o primeiro olhar (título, resumo e/ou palavraschave) para os 501 trabalhos encontrados, restaram-nos 36 produções acadêmicas que poderiam estar em consonância e dialogar com a temática de nossa pesquisa. Apesar de todos os esforços de pesquisa apresentados, nossa revisão evidenciou que há lacunas das agendas de pesquisas que trabalham as relações temáticas: Educação Intercultural, Diálogos Interculturais e Ensino de Ciências, em âmbito de pós-graduação, o que revela a necessidade do desenvolvimento de mais pesquisas no sentido de avançar o entendimento sobre como tem ocorrido tais relações no contexto nacional.

Uma educação intercultural ocorre no momento em que universos culturais distintos se aproximam e se enriquecem mutuamente por um contato mais horizontalizado entre conhecimentos distintos. Segundo Freire (2010, p. 40), há uma continuidade histórica nas práticas sociais que se desenvolvem nas comunidades, alternando-se em estruturas verticalizadas e horizontalizadas. As organizações verticais se estabelecem quando o 'homem-mundo (sic)' prolonga seu universo cultural pelo mundo da história se caracterizando pela intersubjetividade e a intercomunicação. Esta não ocorre somente no interior de uma "unidade epocal", mas articula tempos históricos distintos em uma estrutura horizontal intercomunicativa.

Ao caracterizar a organização vertical e horizontal do conhecimento, o autor supracitado distingue o pensamento mágico e o pensamento rigoroso. $\mathrm{O}$ pensamento mágico "é o que não o é” e por isso exige um engajamento em "ad-mirar” o fato concreto, em termos do pensamento crítico, para "mirá-lo" de dentro em toda a incerteza e insegurança que configuram seu mundo natural, mas também sociocultural, em que vive o sujeito (Freire, 2010, p. 18). 
O conhecimento rigoroso e, em especial, aquele dito científico ocidental moderno, é dado pela descrição das coisas, é construído por sua fundamentação científica (a partir de leis, teorias, postulados), sendo tratado de maneira impessoal, sempre buscando conferir objetividade às coisas. Adotamos neste artigo a ideia de Conhecimentos Ecológicos Tradicionais, como definição de conhecimento tradicional. Strachulski (2017, p. 3) o aponta como "um conhecimento prático transmitido de geração a geração de forma oral, sustentado pelo relacionamento com as crenças e os valores”. Para o autor o conhecimento tradicional adquirido cotidianamente nos serve da experiência do outro, de modo a aprender e também ensinar algo, promovendo a interação humana e social de modo dinâmico. Já o conhecimento científico "apresenta-se tanto como empírico, racional, tendo sua importância no fato de abordar os fenômenos da realidade de forma sistemática, metodologicamente testada, permitindo análise e síntese de informações" (Strachulski, 2017, p. 3).

A sabedoria, o pensamento mágico ou o conhecimento tradicional não são pré-lógicos ou ilógicos, são formas de organização assentadas em uma linguagem e uma estrutura como forma de pensar. Em outras palavras, possuem bases ontológicas e epistemológicas associadas às formas distintas daquelas denominadas ocidentais modernas, ao interpretar os fenômenos da vida concreta. A possibilidade do diálogo entre diferentes culturas, neste sentido, se dá a partir do reconhecimento desta pluralidade epistêmica, que opera na diversidade característica da sociedade brasileira.

Há de se considerar a problemática da colonialidade, que caracteriza o pensamento ocidental moderno. Assim, a entrada dos conhecimentos científicos ecológicos ou como nos diz Freire (2010, p. 9), o conhecimento técnico, chegam às comunidades de forma invasiva, submetendo o ordenamento do pensamento local à sua própria lógica. É como se o pensamento mágico necessitasse de uma "missão civilizatória", para que se torne útil ao desenvolvimento e modernização da comunidade.

Essa noção do pensamento antidialógico, tem o intuito de substituir o conhecimento local. Parte-se do argumento que não se pode "perder tempo" com processos dialógicos de percepção das contradições vividas e de busca de mudanças culturais significativas por parte do sujeito que reafirma, ou (re) admira, o fato concreto que se deseja. Freire (2010, p. 19) relata que, quando o pensamento mágico é vencido pelo pensamento que o invade, reage em formas de expressões sincréticas. Assim, não é que não haja o pensamento crítico ou haja subserviência por parte dos povos do campo, mas sim táticas ou estratégias de "estar sendo" no mundo.

Tal questão trata-se de uma preocupação importante para se pensar os modelos dos cursos de formação de professores como, por exemplo, na licenciatura em Educação do Campo. É nas vivências dos licenciandos em diferentes situações, na Universidade e em suas comunidades, que se constitui o signo-significante que se torna objeto do conhecimento. Um objeto envolto na relação intersubjetiva entre dois sujeitos, mediadas pelo objeto cognoscente. É neste sentido freiriano do ato comunicativo, dialógico, que se compreendem os diálogos interculturais da formação de professores de ciências. 
Por um lado, o contato professor-aluno e as discussões sobre os conhecimentos e conceitos não ficam restritos à universidade, promovendo uma aproximação entre conhecimentos tradicionais e conhecimentos científicos, como retratado por Crepalde e Aguiar Jr. (2014), em um trabalho sobre a temática energia no contexto do campo. Por outro lado, este movimento de alternância universidade-comunidade, aproxima diferentes formas de vivência de mundo e culturas, nas quais "educar na diversidade é ensinar e aprender junto com os alunos a conviver com pessoas, destacando nossas diferenças físicas, sociais e culturais" (Cardoso, 2014, p. 4).

Desta forma, o olhar para a construção do ensino de ciências a partir relação campo-universidade, respeitando as diferenças e considerando a multiplicidade de culturas pode representar um ensino pautado em diálogos interculturais de educação, ou ainda, de acordo com Candau (2003), a interculturalidade busca promover relações dialógicas e igualitárias entre pessoas que pertencem a universos culturais diferentes.

O olhar deste artigo, então, recai sobre três momentos: a participante, a comunidade local da participante e o aporte teórico fundamentado nas "pontes entre Conhecimentos Científicos Escolares (CCE) e Conhecimentos Ecológicos Tradicionais (CET)". Ao pensar em diversidade cultural no ensino e aprendizagem de ciências Molina \& Mojica (2013) propõe, também pensando na ideia das pontes, uma abordagem que proporcione o desenvolvimento de processos que comuniquem o mundo da ciência escolar com o mundo pessoal dos alunos, os quais podem ser configurados colocando distintos sistemas de conhecimento em um mesmo âmbito e compreendendo os processos simbólicos implicados.

Melo (2017, p. 55) também se apropria da ideia do uso de pontes no ensino de ciências como um "compromisso para compreender as investigações sobre as relações entre conhecimentos científicos escolares e conhecimentos ecológicos tradicionais", representando assim, segundo a autora, um viés de perspectiva intercultural em que os conhecimentos se situam em um mesmo nível de complexidade e relevância, a partir de um contexto local culturalmente distinto e que propicia uma interação na heterogeneidade existente nos processos educativos. A autora ainda defende que as pontes demarcam as diferenças, fortalecendo assim o diálogo intercultural que "podem ser estabelecidos entre diferentes culturas e tradições, culturas acadêmicas e profissionais".

Neste trabalho não apresentaremos todas as análises relativas às pontes entre conhecimentos, que compreendem quatro perspectivas: perspectiva assimilacionista (conhecimento científico como ponto de partida, CCE); perspectiva moral e humanista (centrada no conhecimento do outro); perspectiva plural epistêmica e ontológica (aspectos epistêmicos e do outro) e, perspectiva contextual (aspectos socioculturais e 
CET) (Molina \& Mojica, 2013). Focaremos naquelas que acreditamos evidenciar, de forma mais emblemática, as potencialidades dos diálogos interculturais na formação de professores de ciências do Campo. Com o exposto, os itinerários formativos em alternância de espaços e tempos possibilitam vivências que horizontalizam mais as relações entre professores e alunos, e propiciam pontes e trocas de saberes entre CET e CCE. É justamente neste ponto que buscamos investigar as relações interculturais que permeiam esta relação, porém especificamente a partir do acompanhamento in loco de nossa participante (em diferentes espaços e tempos) e atentando para o desenvolvimento de seu TCC sobre a temática cafés especiais e os conhecimentos que podem ser trabalhados na escola.

\section{A comunidade tradicional Geraizeira e o delineamento metodológico da pesquisa}

Uma das localidades do campo na qual a Lecampo/UFTM atua, é a Comunidade Tradicional Geraizeira de Pindaíba, localizada a $50 \mathrm{~km}$ do município de Rio Pardo de Minas, Minas Gerais. Segundo o Instituto Brasileiro de Geografia e Estatística (IBGE) o município de Rio Pardo de Minas está localizado em uma região montanhosa da microrregião de Salinas (Figura 1), próximo a Serra Geral. É banhado pelos rios Preto e Pardo, com águas lamacentas de cor parda, o que originou o nome da cidade, que possui atualmente cerca de 29.000 habitantes. Na região, onde o destaque é a rica biodiversidade da flora e fauna, a vegetação presente é uma transição entre os biomas Cerrado e Caatinga.

Toda sua economia gira em torno da agricultura e da mineração, porém, é preciso destacar a forte influência da monocultura de eucalipto na região (Oliveira 2018, p. 22). Sobre esse aspecto, Oliveira (2018) menciona que a cultura de eucalipto cultivado de forma desordenada, tem influenciado toda a região pressionando as comunidades tradicionais ali existentes em pequenos espaços de terra provocando o desaparecimento de muitas nascentes antes existentes no território, contribuindo assim para a escassez de água em alguns locais. Tais comunidades lutam pela sobrevivência através de práticas próprias de plantio e exploração do cerrado que foram herdadas de gerações anteriores e até hoje são aperfeiçoadas, de forma sustentável: esse é o modo de vida Geraizeiro, que tem como princípio o uso comum das terras para desenvolverem atividades agrossilvipastoril e agrossilvicultura, nas quais são associadas a produção de alimentos, criação de animais, aproveitamento de frutas silvestres e plantas medicinais (Veloso et al., 2011). 
Figura 1. Localização da cidade de Rio Pardo de Minas, no estado de Minas Gerais
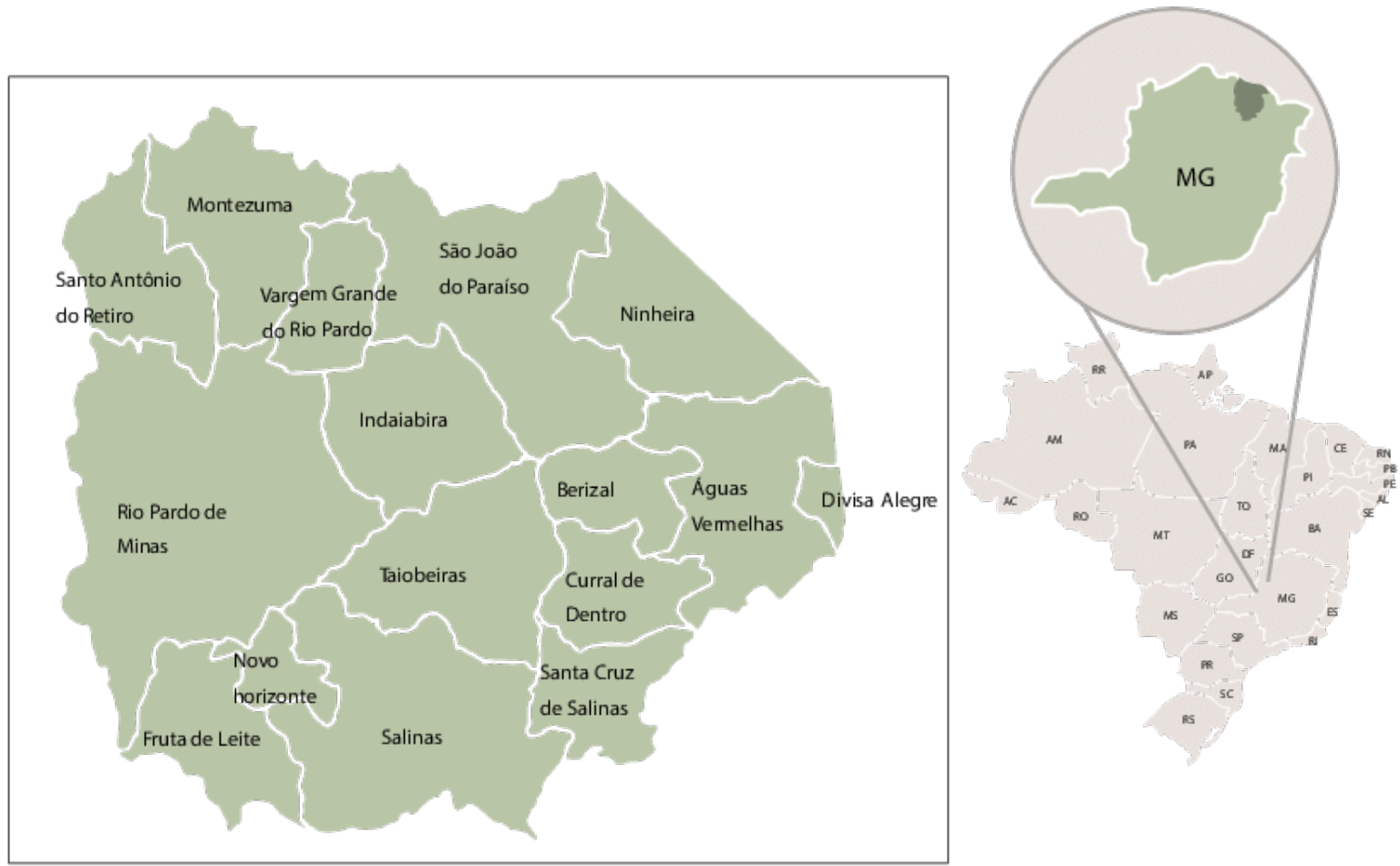

Fonte: Adaptado de Perfil Territorial. Alto do Rio Pardo (2019).

No caso da comunidade em foco, os próprios moradores se mobilizaram a construir sua capela, como um ponto de encontro simbólico tanto para praticarem ações de sua fé (cultos, terços, adoração ao Santíssimo Sacramento) quanto para discutirem sobre suas condições de vida e políticas públicas que permeiam seus modos de vida. Como a capela é um ponto de encontro de todos os moradores, ela também é usada para informes coletivos. Assim, este é um espaço não só religioso, mas também político, típico da organização articulada ao ideário das comunidades eclesiais de base que fazem parte da Igreja Católica Apostólica Romana, e segundo Betto (1981) são pequenos grupos organizados em torno da paróquia (urbana) ou da capela (rural), por iniciativa de leigos, padres ou bispos.

Observamos que, em quase todas as comunidades do local, não há um padre disponível para atender às capelas, fato que conduz os próprios moradores (neste caso o pai da licencianda) a serem nomeados pela igreja católica como Ministros da Eucaristia para guiar as orações e os demais ensinamentos da religião. Contudo, a participante relata que esses momentos de oração também fazem parte de uma ação maior, que é a luta pela tradição dos Geraizeiros na comunidade, pois são realizadas rodas de conversa com reflexões em âmbito social, como também propõe a igreja católica em sua Campanha da Fraternidade (CF) do ano de 2019. É proveniente desta comunidade, a participante principal desta pesquisa: uma aluna do sétimo período da 
Lecampo/UFTM, que demonstrou um grande interesse em desenvolver um TCC sobre os conhecimentos tradicionais envolvidos em seu cotidiano no campo e suas relações com o Ensino de Ciências. A licencianda ingressou na Lecampo em 2016, tem um perfil de aluna trabalhadora (trabalha ativamente no cultivo de cafés sombreados junto à sua família).

A participante, de 25 anos de idade, é muito tímida e reservada. É muito religiosa, estudiosa e sempre busca junto à sua família aperfeiçoar seus conhecimentos para melhorar a qualidade de vida no lugar onde vive, a comunidade de Pindaíba a qual ela demonstra um grande apego. Interessante perceber que o "melhorar de vida" na visão da participante está relacionado a adquirir conhecimentos que sustentem a ampliação e melhoria na produção de cafés mantidas pela sua família. $\mathrm{O}$ afeto e respeito por sua família, mesmo em momentos em que está longe de casa, também fica muito evidente ao observar seus posicionamentos e suas falas.

A temática escolhida pela participante da pesquisa para o TCC foi, a partir do processo de produção tradicional de cafés especiais sombreados, a seleção de algumas práticas agroecológicas como artefatos culturais e discussão das potencialidades dos diálogos interculturais com o ensino de ciências. Assim, adotamos a entrevista semiestruturada como instrumento para apreender essa relação estabelecida pela estudante em seu processo de produção escrita na construção do seu TCC. No roteiro da entrevista foi perguntado sobre a trajetória acadêmica e motivações em sua vivência na Lecampo (dificuldades, desafios, descobertas); sobre as relações entre conhecimentos tradicionais e conhecimentos científicos escolarizados ao longo do curso, bem como sobre a temática do TCC (como surgiu?); foi solicitado também que ela falasse sobre a vida em sua comunidade, descrevesse seu cotidiano e sua realidade no campo; e por fim sobre a formação, em como vislumbrava a atuação após a formatura, e principalmente, como pensava os conhecimentos dos cafés tradicionais para ensinar ciências na sala de aula.

A entrevista ocorreu no contexto de uma imersão etnográfica escolar ${ }^{2}$ na Comunidade Tradicional onde ela vive. Esta imersão aconteceu em abril de 2019, durante as atividades do Tempo-Comunidade juntamente a alguns docentes do curso da Lecampo/UFTM, que acompanharam estágios, realizaram orientações de TCC e outras atividades pertinentes a formação dos licenciandos.

Foram realizadas observações participantes e não-participantes no município de Rio Pardo de Minas e em algumas Comunidades tradicionais a fim de também perceber como se dá o perfil dos alunos da Lecampo/UFTM e da licencianda em questão. Conforme fomos conhecendo as comunidades e procurando estabelecer um contato inicial de diálogo com os moradores locais, foram realizadas várias conversas informais

2 Sobre o conceito de etnografia escolar consideramos uma imersão ao mundo da licencianda, não em nível antropológico, mas em um contexto escolar que neste caso é o curso de licenciatura em Educação do Campo, de acordo com ideias de André $(2005,2009)$ e Restrepo (2018). 
e espontâneas, entrevistas abertas e semiestruturadas com a participante da pesquisa. Também foram elaboradas notas em cadernos de campo. No entanto, grande parte da imersão etnográfica foi destinada a conhecer e experienciar a realidade e modo de vida dos Geraizeiros de Pindaíba. Em um primeiro contato com a comunidade, conhecemos a propriedade onde mora a participante, a plantação de café sombreado onde trabalha e alguns familiares como tios, primos, sua mãe e, como bem demonstrado pela licencianda, sua maior inspiração: o pai.

A fim de amparar o cumprimento dos objetivos e direcionar as observações durante este tempo de acompanhamento na comunidade, foi construída uma Matriz de Observação, adaptada da proposta por Restrepo (2018), na qual buscamos a partir da pergunta de pesquisa, elaborar uma espécie de guia no qual nos permitisse evidenciar quais aspectos poderiam se basear as observações, conforme mostrado na Figura 2. Além da Matriz de Observação também foi construído, ainda de acordo com as ideias de Restrepo (2018), um caderno (ou diário) a fim de registrar e organizar os dados coletados durante o trabalho de campo. Segundo o autor é importante descrever tudo o que é observado: conversas, atividades que estão sendo realizadas, sentimentos provocados naquele instante, experiências. A ideia é "recriar com palavras o que foi observado e experimentado" (p. 67). Também é importante registrar atitudes corporais, tons de voz, gestos, como se iniciou aquele assunto, contexto envolvido, silêncios, ou seja, tudo o que se relaciona ao problema de pesquisa. Este instrumento facilitou a construção dos dados que evidenciam as pontes entre CCE e CET nas interações e movimentos realizados pela licencianda durante as vivências no curso, tanto na comunidade quanto na universidade.

Figura 2. Matriz de observação

\begin{tabular}{|l|l|}
\hline \multirow{3}{*}{ História de vida } & $\begin{array}{l}\text { Descrição: busca conhecer a participante por meio de sua história, vivência, } \\
\text { relações interpessoais com família, comunidade, Universidade. }\end{array}$ \\
\cline { 2 - 2 } & $\begin{array}{l}\text { Pressupostos de observação: } \\
\text { Quão urbana é } \\
\text { Experiência pessoal com a natureza } \\
\text { Discriminação por ser do campo } \\
\text { Visão sobre sua família, religião, escola, Universidade } \\
\text { Componente afetivo e emocional a partir dos interesses e compromissos da } \\
\text { estudante e como se apoiam em sua cultura } \\
\text { Porquê das práticas tradicionais }\end{array}$ \\
\hline
\end{tabular}

Fonte: adaptado de Restrepo, 2018. 
Figura 2. Matriz de observação (cont.)

\begin{tabular}{|c|c|}
\hline \multirow{12}{*}{ Comunidade } & $\begin{array}{l}\text { Descrição: pretende conhecer relações sociais, econômicas e culturais presentes } \\
\text { na comunidade, conflitos inerentes a tais relações, conhecimentos e saberes } \\
\text { herdados e transmitidos na/da comunidade. }\end{array}$ \\
\hline & Pressupostos de observação: \\
\hline & Aspectos da colonização \\
\hline & Aceitar ofertas ocidentais \\
\hline & Hibridez cultural \\
\hline & Superação da exclusão \\
\hline & Formas como usa práticas tradicionais no cotidiano e nas relações sociais \\
\hline & Interações culturais na comunidade \\
\hline & Ações para resolver problemas na comunidade \\
\hline & Emergência de novos objetos de estudo \\
\hline & $\begin{array}{l}\text { Configuração de novas formas acadêmicas e novos modelos de formação } \\
\text { docente }\end{array}$ \\
\hline & Normas, valores, crenças e práticas dentro da comunidade \\
\hline \multirow{8}{*}{ TCC } & $\begin{array}{l}\text { Descrição: objetiva investigar os diálogos que decorrem da vivência da } \\
\text { licencianda na Universidade e na comunidade frente diálogos interculturais. }\end{array}$ \\
\hline & Pressupostos de observação: \\
\hline & Exclusão \\
\hline & Discriminação \\
\hline & Ensino ocidental \\
\hline & Lecampo \\
\hline & $\begin{array}{l}\text { Estabelece diálogos entre Conhecimentos Tradicionais e Conhecimentos } \\
\text { Científicos }\end{array}$ \\
\hline & $\begin{array}{l}\text { Contraste entre a ciência moderna com conhecimentos, crenças e habilidades } \\
\text { de ambientes tradicionais }\end{array}$ \\
\hline \multirow{6}{*}{ Expectativas } & $\begin{array}{l}\text { Descrição: procura levantar as preocupações da participante em relação as } \\
\text { suas expectativas futuras, tanto como professora quanto como membro da } \\
\text { comunidade, frente ao trabalho de pesquisa desenvolvido. }\end{array}$ \\
\hline & Pressupostos de observação: \\
\hline & Está preocupada com problemas ambientais \\
\hline & $\begin{array}{l}\text { Quais seus medos, suas visões sobre a ciência, sobre conhecimentos científicos, } \\
\text { conhecimentos tradicionais, conhecimento ancestral }\end{array}$ \\
\hline & Como se vê professora \\
\hline & Visões sobre o futuro da prática agrícola, religião e ciência \\
\hline
\end{tabular}

Fonte: adaptado de Restrepo, 2018 (cont.). 
Quanto aos aspectos metodológicos, tomamos como base o estudo de caso etnográfico (André, 2009). A pesquisa etnográfica é um tipo de estudo que caracteriza as particularidades de determinados povos ou pessoas, contudo tem se observado que essas descrições vão além de se fixar em certos povos ou minorias étnicas, mas implicam em considerar todo o contexto envolvido, tanto no olhar do pesquisador como também nas lentes do participante. Tais descrições se revelam como "compreensões situadas" (Restrepo, 2018) pois levam em conta "as formas de habitar e imaginar, de fazer e de significar o mundo para certas pessoas" inseridas no contexto do estudo. Para o autor, também deve ser considerado o olhar do pesquisador ao partir de suas "experiências (de observações, conversas, inferências e interpretações), dependendo dos lugares, trajetórias" e relações sociais nas quais os sujeitos da pesquisa estão inseridos e nas tensões que vivenciam (Restrepo, 2018, p. 26).

As análises, tal como já explicitado na seção anterior, está fundamentada em uma perspectiva freiriana do papel da universidade em seu processo de ida a comunidade, e sob a lente das "pontes entre Conhecimentos Científicos Escolares (CCE) e Conhecimentos Ecológicos Tradicionais (CET)" e é usada para "reconhecer a existência de conhecimentos, perspectivas e visões sobre o mundo natural, que possuem comunidades culturalmente diversas" (Molina \& Mojica, 2011, p. 36, tradução nossa).

Tal metodologia tem caráter de pesquisa qualitativa e interpretativa. A ideia de pontes entre conhecimentos aparece como uma metáfora usada para "indicar o mecanismo pela qual a travessia (ida e volta)" pode acontecer nos processos de ensino aprendizagem de ciências considerando o contexto cultural específico dos alunos. Perspectiva esta, que vai ao encontro da noção de comunicação nos processos educativos, tomando como ponto de partida a própria realidade e contradições vividas pelos sujeitos, tal como defendida por Freire (2010, p. 9). A partir da experiência no curso da Lecampo, analisadas na presente pesquisa, emergiram três categorias de análise: Admirando a realidade Geraizeira a partir da Alternância; A dialética da cultura Geraizeira: permanecimento e mudança; e Diálogo interculturais na Lecampo e a necessidade do ato comunicativo, que desvelam a importância do genuíno diálogo entre culturas, no sentido proposto por Freire, quando pensamos a formação de professores e professoras de Ciências em contextos de Educação do Campo. A pesquisa foi autorizada pelo Conselho de Ética em Pesquisa (CEP) da instituição, pelo número 3247613, seguindo todos os parâmetros regulares de ética na pesquisa.

\section{Potencialidades dos diálogos interculturais na Lecampo: da ad-miração à construção de pontes entre conhecimentos}

De maneira genérica, podemos entender cafés especiais sombreados como uma produção agrícola desenvolvida à sombra de outras, com manejo de diferentes produções e controle de podas e sombreamentos de modo a não comprometer a produção. Destaca-se ainda que, o café tradicional também pode ser entendido em um sentido de transmissão de conhecimentos sobre o manejo do café passados de geração para geração, se preservando práticas e hábitos construídos ao longo da história, refletindo, inclusive a caracterização de uma região, povo ou comunidade tradicional. 
Evidencia-se que a licencianda, bem como toda a sua família, se identifica como pertencente aos Geraizeiros e lutam pela conservação da biodiversidade local através de formas próprias de cultivo, sem utilizar insumos químicos. A família toda está envolvida com o plantio de café sombreado, que carrega consigo um intenso envolvimento entre os conhecimentos tradicionais herdados de outras gerações e o melhoramento de técnicas de produção. Tal escolha foi motivada pelo fato dela encontrar contradições e desafios na produção desse café, que também é dito como "especial".

Desta forma, o universo temático se estabelece a partir deste fato sócio-histórico concreto que não se limita a uma "unidade epocal", e o processo de codificação e descodificação indicados por Freire (2010) se traduz do próprio objetivo do TCC da participante. Ela buscava compreender como o Ensino de Ciências pode ser uma ferramenta útil para discutir os conhecimentos tradicionais (implícitos na prática tradicional de plantio e cultivo) e científicos (envolvidos nos processos de ensino aprendizagem).

Neste contexto, em um contínuo processo metodológico, acompanhamos de perto o amadurecimento das ideias nas etapas de construção desse trabalho, o planejamento inicial, reuniões de orientação e construção teórica e trabalho de campo. Este processo foi muito importante para investigar e entender como os diálogos interculturais estão imersos em seu trabalho, uma vez que a licencianda tenta articular suas vivências cotidianas às vivências científicas que traz da Universidade. Nas subseções seguintes a base empírica construída a partir desta imersão etnográfica é organizada a partir de três movimentos importantes do olhar freiriano para sua indaga: comunicação ou extensão? (Freire, 2010), a saber: Ad-mirando a realidade Geraizeira a partir da Alternância; A dialética da cultura Geraizeira: permanecimento e mudança; e Diálogo interculturais na Lecampo e a necessidade do ato comunicativo.

\section{Ad-mirando a realidade Geraizeira a partir da Alternância}

Em uma das bases de sustentação da Lecampo/UFTM encontra-se a dinâmica de Pedagogia da Alternância, a qual relaciona o Tempo-Escola (TE) e o Tempo-Comunidade (TC), como já citado anteriormente. O TC visa reforçar a horizontalidade nas relações professor-aluno, trabalho-aprendizagem, conhecimentos acadêmicos e conhecimento tradicional, a partir da Pedagogia da Alternância. A horizontalidade pressupõe que as relações professor-aluno atentem para a descolonização do saber e superação de uma educação urbanocêntrica hegemônica que não atenda aos anseios da comunidade campesina. Nesta dinâmica, a essência do saber amplia-se para além da Universidade, entendendo o campo como local de produção e socialização de conhecimentos.

Este é um movimento que busca superar a concepção de que o professor é o detentor de todo conhecimento, com implicações para um processo educativo centrado na figura docente e na aula como um evento de transmissão de informes. Esta dinâmica, em que ambos os sujeitos do processo educativo envolvidos na alternância - professor/a da universidade e povos do campo - se encontram inseridos, necessita como ato 
dialógico, o que Freire (2010) considera como "ad-miração" da prática. Segundo ele, a "ad-miração" da realidade, do fato concreto, em termos críticos, permite poder "mirálo" de dentro, captando o desafio em suas relações autênticas com outros fatos e razões explicativas para o dado percebido.

Sobre a produção do café sombreado, durante a entrevista, a participante afirma que utilizam técnicas que aprenderam de gerações anteriores, e também buscam junto à Empresa Brasileira de Pesquisa Agropecuária (EMBRAPA), novas técnicas de manejo para a melhoria da qualidade dos grãos do café. Interessante destacar que no "aprender de gerações" da comunidade em foco estão implícitos os conhecimentos tradicionais que são construídos/herdados na comunidade. Por outro lado, há uma busca constante de atualização e assistência técnica a partir de cursos oferecidos pela EMBRAPA, ela usa a expressão "novas técnicas de manejo" ao fazer referência aos cursos e aparece o contraste frente a conhecimentos científicos que melhorem a produção do café.

Para Freire (2010, p. 7) a relação do agrônomo educador com as comunidades rurais não pode ter um caráter de invasão cultural, como uma visão ingênua da realidade a partir de uma "extensão agrícola", mas deve partir de dentro do contexto cultural da comunidade para mobilizar-se em si e nos sujeitos a ad-miração do objeto do conhecimento. Este processo emerge necessariamente do ato de problematizar o fato concreto, o que torna possível o ato dialógico. Dessa forma, se a busca de "novas técnicas" em cursos da EMBRAPA se configurasse como uma forma de sobreposição dos saberes locais, estaríamos falando de uma visão de extensão criticada pelo autor, contudo o que observamos é que a participante, bem como sua família, coloca a técnica a serviço de seu projeto de vida: a permanência no campo e a valorização de sua cultura com condições de subsistência.

A partir desta investigação, encontramos indícios que pode nos revelar um diálogo entre Conhecimentos Tradicionais e Científicos, ao qual a atualização técnica não pode ser descolada da ação política de manutenção da identidade do campo. O cultivo de café tem grande importância para a comunidade, pois é através dele que os Geraizeiros reafirmam suas tradições e o denominam "cafés especiais", como forma de distinção desta prática cultural em relação às outras formas de produção dos grãos. Assim, através desse universo temático, a participante optou por tratar no seu TCC a relação dos cafés especiais com o Ensino de Ciências.

Inferimos, em nossa vivência na comunidade, que a escolha por trabalhar a relação dos cafés especiais tem como motivação a própria contradição vivida e percebida. $\mathrm{O}$ avanço da monocultura de eucalipto que devasta a região de Rio Pardo de Minas e que tem trazido muitas consequências a esses povos, como a falta d'água, a perda de terra em suas comunidades e outros fatores que fazem com que os moradores locais tenham que ressignificar suas tradições e práticas cotidianas a fim de se adaptar às condições impostas. Assim, melhorar o cultivo do café poderia, sobretudo, ser uma resposta de enfrentamento no sentido de manter viva sua cultura. 
Interessante notar que, ao acompanhar o processo de produção do TCC a participante é enfática ao afirmar que sua grande esperança, e de toda a família, está no cultivo do café sombreado, o qual traz uma forma de produção tradicional e agroecológica, indo na contramão das demandas atuais, uma vez que gera menos capital financeiro. No entanto, em um de seus enunciados "papai não trabalha, plantamos tudo e de vez em quando vendemos algum carvão, mas não passamos fome" (Participante, p. 19 cc), se evidencia uma construção social de que o trabalho é servir ao outro (papai não trabalha), afastando-se da noção de subsistência. Se acrescenta também a fala "não passamos fome", como forma de justificar e reafirmar o "estar sendo" da comunidade.

Segundo Toledo e Barrera-Bassols (2015), é necessário que sejam reconhecidos tanto o conhecimento (aprendido, experimentado e validado) quanto a sabedoria (adquirida através do tempo e das gerações, com a experiência e valores humanos). Esta representação pode ser vista sob o olhar da horizontalidade, e não pela hierarquização do conhecimento, ouseja,oconhecimentocientífico, dialogacomoconhecimentotradicional, situando-se se mais próximo à natureza, e é amparado por crenças, conhecimentos e práticas construídas historicamente sobre ela. $\mathrm{O}$ conhecimento científico, ou rigoroso nas palavras de Freire (2010), por meio de conceitos e teorias presentes nas ciências, busca, então um diálogo com o crer, conhecer e praticar do camponês. Fato é que, tanto o conhecimento tradicional quanto o científico são conhecimentos que trazem em si as ciências, porém com lentes diferentes de ver o mundo ao seu redor, no qual suas aproximações podem representar ampliações do ensino de ciências em meio a diálogos interculturais, o que também pode ser percebido no trabalho da aluna.

Neste sentido, consideramos que as vivências proporcionadas no TC da Lecampo/ UFTM, a partir da organização didático-temporal da alternância, possibilitam que juntos, professores e professoras da universidade, educandos e educandas do curso, em interação com suas comunidades de origem, participam de um processo educativo onde a "ad-miração" da realidade se faz necessária e presente. As aprendizagens do curso, o retorno à comunidade e a retroalimentação de ambos a partir das experiências vividas e "ad-miradas" faz com que outras compreensões sobre as contradições locais e sobre os problemas reais sejam desveladas. Neste processo, também o educador da universidade, problematizado ao problematizar", igualmente "re-ad-mira" o objeto problemático através da "ad-miração" dos educandos. Esta é a razão pela qual o educador continua aprendendo, e, quanto mais humilde seja na "re-ad-miração" que faça através da "admiração" dos educandos, mais aprenderá (Freire, 2010, p. 56).

O professor, na interação com educandos e educandas em suas comunidades, através de um processo realmente dialógico, é fundamental no desvelamento da situação existencial codificada. Por ser uma situação vivida pelos camponeses que, enquanto a viviam, ou não a "ad-miravam" ou, se a "ad-mira-vam", o faziam através de um mero dar-se conta, a descodificação, como um ato cognoscitivo, lhes possibilita "ad-mirar" sua

3 Na obra Extensão ou Comunicação, Freire destaca que no "ato de problematizar os educandos, ele [o educador] se encontra igualmente problematizado" (p. 56). 
não "ad-miração" ou sua "ad-miração" anterior (Freire, 2010). Neste sentido, o processo educativo da alternância de tempos e espaços na Lecampo potencializa a codificação/ descodificação das situações-problema, fazendo com o que o antes não "ad-mirado", agora seja entendido como um "percebido-destacado", ou seja, um os sujeitos do campo, inseridos criticamente na sua realidade, percebem suas contradições e se reconhecem como sujeitos transformadores do mundo em que vivem.

\section{A dialética da cultura Geraizeira: permanecimento e mudança}

Para Freire, "ser homem", no sentido de "ser humano", consiste em "estar sendo" no mundo. Este "estar sendo", por sua vez, envolve sua relação permanente com o mundo e, também, sua ação sobre ele (Freire, 2010, p. 25). Neste sentido, sua presença no/com o mundo pressupõe um permanente defrontar-se com este, com suas contradições e suas transformações. Este movimento dialético envolve, por consequência, a noção do tempo e da duração das coisas, já que "duração não quer dizer permanência, mas o jogo entre permanência e transformação" (Freire, 2010, p. 81). Quando nos referimos a comunidades tradicionais, como o caso dos Geraizeiros, este jogo está sempre presente: a tensão entre o que permanece e o que muda, o que nos caracteriza e o que nos deforma.

É oportuno destacar que sua família planta e colhe em seu pequeno espaço de terra nos fundos do quintal, em um movimento de subsistência, e a relação dos cafés especiais com o Ensino de Ciências, por meio do TCC da educanda participante, poderia trazer novos horizontes, seja para sua formação como professora do campo (unindo o tradicional ao científico) ou para o olhar para a comunidade.

Quando questionamos a participante sobre sua rotina diária, a mesma de imediato buscou relatar que suas irmãs não moram mais na comunidade, (mesmo sem termos questionado sobre) e, enfatizou que o trabalho rural é intenso. Assim, neste contexto vivencial, a participante relata se sentir responsável em ajudar sua família em todos os afazeres enquanto não consegue outro emprego.

Por agora que não está tendo emprego lá [na cidade de Rio Pardo de Minas] eu venho para cá [na comunidade de Pindaíba] para ajudar meus pais, agora que eu estou fazendo estágio eu vou para a escola, de manhã. A tarde eu tento estudar um pouco, mas [fala baixinho] não consigo.... Ah, ajudo meus pais a plantar. O tempo que eu fico aqui, eu fico ajudando meus pais na roça a colher, plantar, limpar [...] aí tem a comunidade que a gente participa no momento de oração [pausa] e vai seguindo a vida né, é assim. (Participante, em entrevista. Grifo nosso)

Quando a participante relata sobre "o tempo que eu fico aqui, eu fico ajudando meus pais na roça" ela demonstra sua preocupação com a família e todo o trabalho envolvido na manutenção da plantação. Também evidencia o sentimento de pertencimento ao local, à roça. Em meio a nossos diálogos e presenciando sua determinação com os afazeres de casa, questionamos o porquê de ter escolhido estudar em um curso de licenciatura em Educação do Campo. Como devolutiva, a participante mencionou que 
sempre teve muita vontade de ajudar as pessoas e, inicialmente, seu sonho era fazer um curso de enfermagem, pois também teria melhores chances de "conseguir um emprego e melhorar a renda da família". A afirmação da participante "conseguir um emprego" antecipa a colocação de "melhorar a renda da família". Notamos, contudo, que esta fala não refletia a vontade da participante, a qual era manter-se na roça, mas que, para ajudar a família aceitaria esta realidade. Tal constatação revela o quão intensa é sua relação com a família, uma vez que o iniciar de um curso de enfermagem na cidade, naturalmente causaria implicações decisivas em seu modo de vida.

Frente ao exposto, é importante perceber a contradição entre o desejo da participante e sua condição concreta. Ir para a Universidade não era um desejo predominante, mas, implicitamente, a intenção se baseava na melhoria das condições financeiras e não necessariamente em uma oportunidade de promover transformações socioculturais necessárias em sua comunidade visando, por exemplo, um projeto político como a reforma agrária popular. Assim, percebe-se, na participante, a afirmação da identidade rural, enfatizando um sentimento a fim de valorizar a cultura para obter o reconhecimento (neste caso financeiro) do outro (hegemônico), indo na contramão da identidade campesina, trazida por Arroyo et al. (2004) como luta contra a inferiorização e racialização dos povos do Campo, luta pela terra e ao projeto popular de desenvolvimento do campo.

Acrescentando-se, ainda, às colocações de Whitaker (2008), nas quais apresenta diferenças centrais entre o ruralismo pedagógico dos anos 1930 e a educação no campo, a autora é enfática ao mencionar que "a educação que se propõe hoje para o campo nada tem a ver com as teses dualistas equivocadas de ideólogos dos pecuaristas e cafeicultores dos anos 1930 - que pretendiam "fixar" o homem do campo" (p. 301), pelo contrário, a educação do campo busca criar possibilidades formativas em direção a aquisição de conhecimentos e diálogos educacionais, sociais e culturais que permitam que o sujeito do campo dialogue em igualdade com todos os setores da sociedade, sem, contudo deixar o campo.

Importante ressaltar também outros pontos que evidenciam o movimento dialético entre permanência e mudança no discurso da licencianda, como no trecho "O tempo que eu fico aqui, eu fico ajudando meus pais na roça a colher, plantar, limpar” há um posicionamento em relação aos saberes e fazeres locais e a relação tempo-espacial da participante com a família. Esta ligação orgânica com a comunidade e com o território caracteriza uma identidade camponesa. Considerando que a licencianda participante da pesquisa é moradora do campo e sobrevive do que a terra oferece, concordamos com as ideias de Toledo e Barrera-Bassols (2015) ao considerarem que homem, natureza e cultura estão ligados entre si por relações entre suas cosmovisões.

Seguindo esta ideia, somos levados a refletir sobre como são adquiridos, reconstruídos e sustentados os conhecimentos tradicionais, tanto em sua vida no campo como na vida universitária. Desta forma, cabe a nós caracterizar tais cosmovisões por meio de nossas percepções sobre os conhecimentos tradicionais dos povos Geraizeiros, 
especialmente em relação à licencianda em sua comunidade. Para que este processo dialógico ocorra, Freire (2010) enfatiza a necessidade de compreendermos o ato educativo em interação com a comunidade do campo como um processo comunicativo e não extensivo, no sentido de "levar" o conhecimento a alguém que não o tem.

Durante os momentos de convívio em que estivemos em contato com a licencianda, foi observado que as crenças, por exemplo, estão presentes em muitos momentos de sua vida, tanto em relação à aspectos relacionados à sua luta, enquanto Geraizeira, quanto à sua religiosidade. Sobre este último aspecto, observamos e registramos em caderno de campo vários elementos que demarcam a presença da religiosidade como um sustento para reflexões sobre o modo de vida do povo Geraizeiro. Também compreendemos como eles se sustentam na fé para que permaneçam na luta pela valorização e continuidade de seus costumes e tradições, fato verificado, por exemplo, logo ao chegar na casa da licencianda onde havia em cima da mesa da cozinha dois livros e um folheto usados em celebrações da igreja católica. A presença daqueles objetos da maneira como estavam dispostos na mesa, trazia a impressão de que alguém teria acabado de realizar aquelas leituras.

A participante da pesquisa relata que também participa ativamente desses momentos religiosos. Tais momentos são riquíssimos, pois como a maioria dos moradores mais velhos não tiveram acesso aos estudos quase nunca saem da comunidade. Desta forma, ela e outros moradores da comunidade, têm a oportunidade de contribuir com suas experiências vivenciadas na universidade (por exemplo) no sentido de mostrar como a realidade do campo é vista na cidade/universidade e como a educação pode ser uma ponte para que esses diálogos aconteçam.

Ficou nítido para nós, também, a impossibilidade de separar as práticas religiosas, muitas vezes veladas nas pesquisas de campo, com os interesses de nossa investigação, uma vez que ao buscar melhor entender como se entrelaçam os conhecimentos tradicionais e científicos estão imersas memórias bioculturais (Kosmos - crenças, Corpus - conhecimentos, Práxis - práticas (KCP), das quais a religiosidade é uma delas. Recordando sobre a reflexão de memória biocultural, Toledo e Barrera-Bassols (2015), sugere que somos seres sociais, que mantemos vínculos tanto societários quanto com a natureza, por meio de relações que sustentam o entender, valorizar e avaliar experiências históricas. Nas palavras de Toledo e Barrera-Bassols (2015): "O conhecimento tradicional deve ser considerado em sua íntima relação com seu sistema de crenças" (p. 141).

Sobre o desenvolvimento do TCC, a participante da pesquisa ressalta que em âmbito acadêmico (na universidade) precisa com frequência de ajuda para entender o tema do trabalho (p. 14) e a linguagem acadêmica necessária à escrita. O título do trabalho adotado pela participante foi: A prática da produção de cafés especiais por Geraizeiros da comunidade de Pindaíba e suas potencialidades para o ensino de ciências no campo. As dificuldades foram utilizadas como justificativa para que a aluna propusesse a troca do tema, e que finalizasse seu TCC a partir do relato sobre 
seu estágio e não do tema proposto inicialmente. Entendemos que a dificuldade não está atrelada a temática do trabalho, mas nas construções e linguagens acadêmicas próprias de um trabalho científico, dificuldade que é natural e muito frequente entre os alunos de diferentes cursos de graduação no momento da redação de seus relatórios de pesquisa. Este aspecto também evidencia um movimento dialético de permanência e mudança próprios do movimento da participante durante suas vivências nos modelos de alternância da Lecampo.

\section{Diálogo interculturais na Lecampo e a necessidade do ato comunicativo}

Destacamos, a seguir, alguns trechos extraídos das análises que a participante realizou em seu TCC, somados de nossas reflexões e observações que mostram como os saberes tradicionais relacionados ao café dialogam com o conhecimento científico ecológico e escolarizado, ou seja, como a licencianda reconhece em suas próprias tradições a presença da ciência. Ao acompanhar o trabalho de campo da licencianda foi possível registrar momentos em que realizava entrevistas com familiares. Quando a participante pergunta a seu tio sobre técnica de manejo de café na qual não se usa defensivos agrícolas, ele fala sobre uma mistura cuja receita vem sendo repassada por sua família a muitos anos:

A calda bordalesa ela leva, bastante coisa, ela tem, sulfato de zinco, sulfato de cobre e cal, cal virgem, e aí você coloca na agua, mistura e deixa para o outro dia, só usar no outro dia e se você usar no mesmo dia ela tem química, né... aí você coloca um ferro dentro para poder testar ela se ela está agressiva, aí se ela [a calda] não enferrujar o ferro que você coloca dentro, ela está pronta para usar, aí você pode usar (Tio da participante, registro do TCC).

O relato apresentado traz uma riqueza de detalhes que evidencia o encontro entre o conhecimento ecológico tradicional e o conhecimento científico ecológico. A calda bordalesa, por exemplo, tem eficiência comprovada sobre diversas doenças fúngicas. No entanto, é fato que o tio da participante tem esta percepção de eficácia a partir de seu uso cotidiano, em uma receita mantida pela sua família. Este é um movimento interessante na agricultura de subsistência, mas que também esconde perigos que podem não ser revelados apenas pela prática do uso. A presença de sulfato de cobre na mistura também pode desequilibrar o ambiente através da lixiviação (extração de constituintes químicos) do solo, diminuindo as minhocas, por exemplo. Ou ainda, a calda pronta, quando utilizada em excesso pode trazer danos para rios, poluindo e causando mortandade de peixes. Estas são noções trazidas pelo conhecimento científico que, quando em aproximação com o conhecimento tradicional podem gerar frutíferos diálogos interculturais na formação desta professora de ciências do campo. Estes foram aspectos explorados pela participante no ato de escritura de seu relatório de TCC como diálogos interculturais potenciais para a escola do campo e para a formação de professores. 
Ao expressar "coloca um ferro dentro para poder testar ela se ela está agressiva, aí se ela [a calda] não enferrujar o ferro que você coloca dentro, ela está pronta para usar", o tio da participante, em seu discurso, se aproxima de um importante conceito químico, a oxidação. Ou seja, a ferrugem resulta da oxidação do ferro. Interessante notar que no relatório de TCC a participante descreve que a tal oxidação é relatada no conhecimento tradicional (e nesta situação) como uma ação da calda agressiva. Esta também pode ser uma interpretação interessante, do ponto de vista pedagógico, para oxidação, uma agressão ao ferro, ou na visão da ciência uma redução do oxigênio que resulta na ferrugem. Podemos inferir que há a tomada de consciência por parte da licencianda do movimento de descodificação próprios da situação gnosiológica de uma educação para a liberdade do sujeito.

Este pequeno trecho de fala da entrevista, selecionado pela participante para seu TCC, evidencia o valor sociocultural que pode ocorrer na aproximação entre o conhecimento tradicional e científico, aproximação que pode ser colocada em movimento a partir da metáfora das pontes entre conhecimentos, que se estabelecem em uma dinâmica de ir e vir e uma negociação contínua entre linguagens, pensamentos e culturas. Essa perspectiva relacional do ato comunicativo, assumindo uma atitude de respeito as visões de mundo e culturas, podem propiciar riquíssimos diálogos interculturais. Assim, o olhar para as colocações e explicações técnicas sobre o manejo de café nos revela uma memória biocultural, no sentido de Toledo \& Barrera-Bassols (2015), no qual as relações entre crenças (a calda bordalesa funciona), conhecimentos (técnica de preparo repassadas pela família) e práticas (o manejo do café) (KCP) fomentam o entendimento, e valorização de experiências históricas presentes na comunidade.

Frente a isso, concordamos com Freire (2010) de que não há como negar que um diálogo verdadeiramente comunicativo, intercultural e sobretudo, que vise uma educação popular, deve buscar, seja no campo dos conhecimentos agrícolas/agrários, seja no campo religioso, seja nos conhecimentos científicos escolares, deve buscar um objetivo fundamental: o da problematização homem-mundo possibilitar que estes aprofundem sua tomada de consciência da realidade na qual e com a qual estão. Em uma perspectiva plural epistêmica e ontológica, tornam-se mais claras as pontes entre Conhecimento Científico e Conhecimentos Tradicionais, uma vez que a construção do conhecimento e o olhar intrínseco para esta construção sustentam a tônica dos discursos e interpretações. Nesta ponte, também não se trata apenas de reconhecer o lugar de cada um, mas de reconhecer para superar os colonialismos, o que sugere uma educação intercultural para a decolonidade.

Em determinados momentos de nossos diálogos, as falas da participante revelam seu contentamento com o curso (Lecampo, na universidade) e com o sentimento de pertencimento do local de fala, ou seja, do não esquecimento de suas origens e tradições:

O bom que eu gostei nesse curso foi isso, é que não descarta o conhecimento que a gente leva [da comunidade] né, que é o tradicional, que os nossos pais passam para gente e que a gente vive aqui na comunidade. E a gente vê que o científico tem um pouco a ver também com o tradicional né, a gente pensava assim ah... 
o nome científico é chique né! $\mathrm{O}$ tradicional a gente achava assim que não tinha valor... e tem muito valor, é muito importante, a gente não pode desvalorizar aquele conhecimento tradicional né, e nem o científico, porque cada um tem o seu embasamento, seu lugar né. (Participante, em entrevista)

Quando a participante menciona "a gente vê que o científico tem um pouco a ver também com o tradicional”, promove uma ruptura arraigada em manuais didáticos e noções de senso comum de não enxergar as interligações entre tradicional e científico. Acrescenta-se ainda o fato de mencionar claramente a convicção de que não se "pode desvalorizar [o] conhecimento tradicional [...] e nem o científico, porque cada um tem o seu embasamento, [tem] seu lugar". Estas são constatações que permitem inferir o amadurecimento da participante no sentido de transitar do tradicional para o científico e vice-versa.

É oportuno recordar que assumimos diálogos interculturais como sendo entendidos em uma perspectiva de diálogo entre culturas (das relações de poder existentes entre as diferentes culturas) neste caso entre a cultura do campo e a cultura da universidade, pautada pelo ensino de ciências. Ao mencionar que o curso "não descarta o conhecimento que a gente leva" explicita o reconhecimento de diferentes formas de conhecimento e os seus modos de expressão, costumes e tradições, mas ainda assim percebe-se a relação de submissão sentida pela participante em relação ao ensino oferecido pela universidade.

A afirmação de que "o tradicional a gente achava, assim, que não tinha valor... e tem muito valor, é muito importante" nos propicia diferentes reflexões. Uma delas caminha no sentido de evidenciar a ocorrência de diálogos interculturais no Tempoescola, a partir do que é trazido da comunidade participante e o apresentado na universidade, pelos professores. Importante salientar que a estudante abandonou o tema do TCC próximo a data da defesa. Justificou a partir da dificuldade em estabelecer as aproximações entre o conhecimento científico escolarizado e as práticas na comunidade, como o caso do café e da rapadura. Em um momento da entrevista chegou a relatar que "não sabia que o que faziam em casa era tão importante de forma que merecesse ser estudado na universidade”. Assim, finaliza o curso aproveitando o relatório de estágio supervisionado realizado na escola, ainda que o texto do TCC sobre café sombreado estivesse praticamente finalizado.

Outra reflexão que a afirmação nos sugere, está ligada à menção “[...] cada um [conhecimento] tem o seu embasamento, seu lugar né”. Esta afirmação amplia a ideia de diálogos interculturais, desconstruindo a dominação de uma cultura erudita (no caso acadêmica) frente a cultura popular (da comunidade tradicional). Aliás, coloca os diferentes conhecimentos tradicional e científico em um mesmo patamar de igualdade, um fato fortemente indicado pela literatura como forma de propiciar a interculturalidade (Candau, 2003, p. 148). 


\section{Considerações Finais}

Abordamos, neste estudo, as potencialidades dos diálogos interculturais na formação de professores e professoras de ciências. Destacamos, neste sentido, o contexto formativo da Licenciatura em Educação do Campo e as múltiplas especificidades deste curso, que a nosso ver, mostra-se como um espaço profícuo para promoção do diálogo intercultural enquanto ato essencialmente comunicativo, conforme trazido por Freire, em sua obra.

Em nossa compreensão, os resultados encontrados nesse estudo contribuem para avançar nas discussões relacionadas ao diálogo intercultural - entre conhecimentos tradicionais e conhecimentos científicos - no contexto da Educação do Campo, considerando o Ensino de Ciências. Isso deve-se ao fato, principalmente, de pautar as categorias freirianas de dialogicidade e comunicação como essenciais para que que as visões de mundo dos povos tradicionais não sejam simplesmente negligenciadas a favor de uma ciência pretensamente neutra e infalível. Neste sentido, o presente estudo contribui, também, para as pesquisas que articulam a área de investigação em Ensino de Ciências articulada à Educação do Campo, fornecendo um exemplar de como o diálogo intercultural entre Universidade e povos do campo pode se fazer presente no cotidiano concreto das LEDOC, mesmo com todas as limitações e desafios que essa modalidade de formação tem enfrentada no contexto das instituições de ensino brasileiras.

Características da Licenciatura em Educação do Campo, tais como, a necessária imersão nos espaços comunitários, tanto por estudantes das licenciaturas quanto pelos docentes que atuam neste curso; a organização didático-metodológica pautada na Pedagogia da Alternância; o público-alvo direcionado aos povos e comunidades do campo, das águas e das florestas; a formação por área de conhecimento; e por último, mas não menos importante, a formação pautada em um ideal emancipatório que preza pela soberania alimentar e pela reforma agrária popular, conduzem a processos formativos em que o diálogo torna-se fator imprescindível.

Outrossim, o reconhecimento da participante da pesquisa sobre a relação entre o Conhecimento Tradicional e o Científico Escolar fica evidente ao longo do processo de leitura, escrita e vivências do regime de alternância. Por ser concluinte do curso, apontamos que a escrita do TCC, em que haja a tomada de consciência sobre as possibilidades de diálogos entre os conhecimentos distintos, mostra-se como potencial elemento formativo quando vislumbramos pedagogias críticas. Os dados mostram a demarcação da própria natureza da ciência, como sua linguagem, por exemplo, é percebido pela participante a partir do contexto de vivências e em relação aos saberes locais. O reconhecimento dos saberes e fazeres dos povos tradicionais Geraizeiros, para além de uma simples acomodação aos conteúdos científicos escolares, exige dos contextos de formação na Universidade, posturas comunicativas e não extensionistas, no sentido pontuado por Freire, de "levar o conhecimento àquele que não o tem". Dessa maneira, a formação de professores e professoras, em especial no contexto da Educação do Campo, não pode estar alheia às subjetividades, às cosmologias, crenças e contradições presentes na prática e na memória das comunidades tradicionais. 
A pesquisa evidenciou que, na produção escrita da licencianda, a busca por conhecimentos que "conversem" com os tradicionais mantidos nas comunidades é recorrente entre os campesinos, o que foi relatado em diversos momentos pela participante, como cursos realizados na EMBRAPA. Interessante foi perceber que, por um lado, a participante defende o não uso de defensivos agrícolas nas plantações de café sombreado em sua comunidade com a manutenção de práticas tradicionais e por outro, alimentam o desejo de reconhecimento por parte de instituições, tal como a universidade, e que representam formas de ascensão financeira, ainda que seguindo uma lógica do discurso hegemônico e de uma identidade rural que fixa o sujeito no campo por meio de uma visão tecnicista da educação. Ressaltamos ainda, que essas contradições percebidas podem ser utilizadas no currículo do curso de Licenciatura em Educação do Campo e, sendo muito importantes, devem ser trazidas para o cerne do processo formativo.

Nesse sentido, reafirmamos a ideia de identidade rural proposta por Whitaker (2008), ao discutir sobre o se fixar no campo e a identidade do campo (nas premissas da Educação do Campo) que reconhece o caráter político e crítico dos diálogos interculturais. Enfim, consideramos que os diálogos interculturais não são apresentados de forma direta, em especial se tratando do ensino de ciências no contexto do campo e, colocam-se como difíceis de serem percebidos, sendo sua identificação um trabalho que requer tempo, esforços, imersões e profundas reflexões, ou seja, a Alternância deve articular ensino-pesquisa-extensão para que seja efetiva e se basear nos preceitos da Educação do Campo. Estas são considerações que abrem novos caminhos para outras pesquisas no sentido de contribuir para melhor entender como a educação intercultural se faz presente no processo de formação de alunos da Lecampo.

\section{Referências}

Andrade, B. S., Andrade, B. S., Hoffmann, M. B., \& Schirmer, S. B. (25-28 de junho, 2019). Educação do Campo e a pesquisa em Ensino de Ciências: uma análise nos ENPEC. XII Encontro Nacional de Pesquisa em Educação em Ciências (XII ENPEC). Universidade Federal do Rio Grande do Norte, Natal, Rio Grande do Norte.

André, M. E. D. A. (2005). Estudo de caso em pesquisa e avaliação educacional. Liberlivros. Arroyo, M. G., Caldart, R. S., \& Molina, M. C.(2004). Por uma educação do campo. Vozes. Betto, F. (1981). O que é Comunidade Eclesial de Base. http://www.dhnet.org.br/direitos/ militantes/freibetto/livro_betto_o_que_e_cebs.pdf

Brick, E. M., Pernambuco, M. M., Silva, A. F. G., \& Delizoicov, D. (2014). Paulo Freire: interfaces entre Ensino de Ciências Naturais e Educação do Campo. In M. C. Molina (Org.), Licenciaturas em Educação do Campo e o ensino de Ciências Naturais: desafios à promoção do trabalho docente interdisciplinar ( $1^{\text {a }}$ ed., pp. 23-60). MDA. 
Candau, V. M. (2003). Didática e multiculturalismo: uma aproximação. In V. M. Lisita \& L. F. Sousa (Orgs.), Políticas educacionais, práticas escolares e alternativas de inclusão escolar. XI Endipe/Alternativa/DP\&A.

Freire, P. (1986). Medo e Ousadia - O Cotidiano do Professor. Paz e Terra.

Freire, P. (2003). Pedagogia do Oprimido (36a ed.). Paz e Terra.

Freire, P. (2010). Extensão ou Comunicação? (14ª ed.). Paz e Terra.

Melzer, E. E. M., Brick, E. M., \& Hoffmann, M. B. (2021). Desafios e potencialidades da área de ciências da natureza nas licenciaturas em Educação do Campo (Ledoc) do sul do Brasil. Revista da FAEEBA - Educação e Contemporaneidade, 30(61), 178-192. https:// doi.org/10.21879/faeeba2358-0194.2021.v30.n61.p178-192

Molina, M. (2015). Expansão das licenciaturas em Educação do Campo: desafios e potencialidades. Educar em Revista, 0(55), 145-166. https://doi.org/10.1590/01044060.39849

Molina, A., \& Mojica, L. (2011). Alteridad, diversidad cultural y enseñanza de las ciencias: Perspectivas de los profesores. Educación y Ciudad, 21(3), 30-44. https://doi. org/10.36737/01230425.n21.104

Molina, A., \& Mojica, L. (2013). Enzeñanza como puente entre conocimentos científicos escolares y conocimientos ecológicos tradicionales. magis, Revista Internacional de Investigación en Educación, 6(12), 37-53. https://revistas.javeriana.edu.co/index.php/ MAGIS/article/view/7200

Nogueira, M. C. R. (2009). Gerais a dentro e a fora: identidade e territorialidade entre Geraizeiros do Norte de Minas Gerais (Tese de Doutorado, Universidade de Brasília, Brasília, Distrito Federal). Repositório Institucional da UnB. https://repositorio.unb.br/ handle/10482/4614

Oliveira, R. R.(2018). Consequências da chegada da monocultura do eucalipto: investigando mudanças nas relações de trabalho e nas relações com a terra na comunidade Pindaíba Rio Pardo de Minas. (Trabalho de Conclusão de Curso, Universidade Federal de Minas Gerais, Belo Horizonte, Minas Gerais).

Pereira, S. S., Miranda, E. R. S., \& Lemes, A. F. G. (2020). Os saberes geraizeiros em sala de aula: algumas proposições a partir da perspectiva freiriana. In A. F. G. Lemes, C. H. S. Castro, C. S. Almeida, \& O. O. Fraile (Org), Os vales que educam: 10 anos de alternâncias, autonomia e diálogos na Educação do Campo (pp. 51-80). Pedro \& João Editores.

Restrepo, E. (2018). Etnografía: Alcances, técnicas y éticas. Fondo Editorial de la Universidad Nacional Mayor de San Marcos.

Toledo, V. M., \& Barrera-Bassols, N. (2015). A memória biocultural: a importância ecológica das sabedorias tradicionais. Expressão Popular. 
Universidade Federal do Triângulo Mineiro (UFTM) (2014). Projeto Pedagógico Curso de Graduação em Licenciatura do Campo (Lecampo). http://www.uftm.edu.br/ licenciatura-em-educacao-do-campo/projeto-pedagogico

Veloso, G. A., Fonseca, A. I. A., Reis, E. F. R., \& Vieira, G. R. A. L. (2011). A monocultura do eucalipto no município de Rio Pardo de Minas e seus impactos na produção agroecológica das populações tradicionais. Cadernos de Agroecologia, 6(2), 11-16. http://revistas.aba-agroecologia.org.br/index.php/cad/article/view/12638

Whitaker, D. C. A. (2008). Educação rural: da razão dualista, à razão dialética. Retratos De Assentamentos, 11(1), 295-304. https://retratosdeassentamentos.com/index.php/ retratos/article/view/26

\author{
Danilo Seithi Kato \\ Universidade Federal do Triângulo Mineiro \\ Uberaba, Minas Gerais, Brasil \\ katosdan@yahoo.com.br \\ Daniela Corsino Sandron \\ Secretaria Municipal de Educação \\ Uberaba, Minas Gerais, Brasil \\ danielasandron@gmail.com \\ Marilisa Bialvo Hoffmann \\ Universidade Federal do Rio Grande do Sul \\ Porto Alegre, Rio Grande do Sul, Brasil \\ marilisa.ufrgs@gmail.com
}

Editora Responsável

Stefannie Ibraim

Manifestação de Atenção às Boas Práticas Científicas e de Isenção de Interesse

Os autores declaram ter cuidado de aspectos éticos ao longo do desenvolvimento da pesquisa e não ter qualquer interesse concorrente ou relações pessoais que possam ter influenciado o trabalho relatado no texto. 